WellBeing International

WBI Studies Repository

$1-1982$

\title{
Behavioral Ecology of Coyotes: Social Organization, Rearing Patterns, Space Use, and Resource Defense
}

Marc Bekoff

University of Colorado

Michael C. Wells

University of Colorado

Follow this and additional works at: https://www.wellbeingintlstudiesrepository.org/acwp_ena

Part of the Animal Studies Commons, Behavior and Ethology Commons, and the Comparative Psychology Commons

\section{Recommended Citation}

Bekoff, M., \& Wells, M. C. (1982). Behavioral ecology of coyotes: social organization, rearing patterns, space use, and resource defense. Zeitschrift für Tierpsychologie, 60(4), 281-305.

This material is brought to you for free and open access by WellBeing International. It has been accepted for inclusion by an authorized administrator of the WBI Studies Repository. For more information, please contact wbisr-info@wellbeingintl.org.

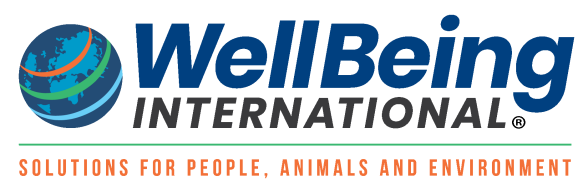




\title{
Behavioral Ecology of Coyotes: Social Organization, Rearing Patterns, Space Use, and Resource Defense
}

\author{
Marc Bekoff and Michael C. Wells
}

University of Colorado

\section{ABSTRACT AND SUMMARY}

Two groups of coyotes in which genealogical relationships were known were studied in the Grand Teton National Park, outside of Jackson, Wyoming, U.S.A., from 1977-1982. One group, a pack consisting of parents and some non-dispersing and non-breeding offspring, defended a territory and the food (mainly elk carrion) contained within it, especially during winter, and also had helpers at den sites (5 of 6 were males). The other group, a mated resident pair, all of whose young dispersed during the first year of life, did not defend a territory and never had helpers at dens. Delayed dispersal and retention of some offspring as helpers was related to the presence of an abundant, clumped, and defendable winter food resource. Dispersing yearlings suffered higher mortality than did non-dispersing individuals.

Litter size was the same for the pack and resident pair; litter size was not significantly correlated with number of adults in the group or with the number or percentage of pups that survived to 5-6 months of age. The presence of pack helpers was not significantly correlated with pup survival, although there was a positive correlation $\left(r_{s}=+0.37\right)$ between the number of adults attending a den(s) and pup survival. Helpers rarely fed pups and their presence had no appreciable effect on juvenile weight. Helpers partook in den-sitting (pup-guarding), but they did not reduce the amount of time that parents spent at den sites. Helpers also actively initiated and took part in territorial and food defense. The proportion of times that pack members initiated defense was inversely related to intruder density $(r=-0.94)$.

It appears that the main advantage of helpers' presence during the time when pups are around is increased protection of young against potential predators. Helpers' sharing of territorial and food defense during winter also is important. From a helper's point of view (for example male B2-1), delayed dispersal from the natal area may increase the likelihood of inheriting a breeding area in which food resources are abundant; mating with a group member or unfamiliar individual is possible. Help may also be received from individuals to whom care had previously been provided. The positive, but non-significant, increase in pup survival associated with helpers' presence also must be considered. The risks associated with early dispersal, low initial reproductive success, and the low probability of inheriting a breeding area are related to observed individual dispersal polymorphisms in coyotes when ecological conditions, especially winter food supply, are sufficient to support a mated pair and some offspring.

\section{Introduction}

By studying conspecifics that display contrasting patterns of social organization, insights may be gained into the factors responsible for observed variations in different types of behavior. Here we are concerned 
mainly with pup-rearing patterns of coyotes (Canis latrans) living either as part of a pack (communal rearing) in which there are non-breeding helpers, or as a resident pair with no helpers. Related behavioral patterns such as space use and resource defense also will be considered.

Comparative research on the communal rearing of young individuals by conspecifics other than parents [helping (SKUTCH 1935, 1961), or alloparental behavior (WILSON 1975)] has grown rapidly in the past few years because of its obvious relationship to theories concerned with the evolution of social behavior (HAMILTON 1964; WILSON 1975; KLEIMAN 1977; BROWN 1978, 1980, 1982 a; EMLEN 1978, 1982 a, b; VEHRENCAMP 1979; BOORMAN and LEVITT 1980; WITTENBERGER and TILSON 1980; ALEXANDER and TINKLE 1981). The most substantive data exist for a small variety of birds (for reviews see BROWN 1978, 1980; EMLEN 1978, 1981; BROWN and BROWN 1981; KOENIG and PITELKA 1981; LIGON 1981; ROWLEY 1981; WOOLFENDEN 1981; and references therein; fora discussion of fish see TABORSKY and LIMBERGER 1981). Comparative field information also is available for a few mammals, including social carnivores [RYDEN 1975; BERTRAM 1976; CAMENZIND 1978; ROOD 1978; FRAME et al. 1979; LAMPRECHT 1979; MALCOLM 1979; MOEHLMAN 1979, 1981, 1982 (also see MONTGOMERIE 1981); OWENS and OWENS 1979; MACDONALD 1980; TULLAR and BERCHIELLI 1980; VON SCHANTZ 1981a, b; HARRINGTON and MECH 1982; HARRINGTON et al. subm. 1982; MALCOLM and MARTEN 1982).

In coyotes and some other social carnivores in which non-parent group members help to rear young individuals, helpers typically do not breed, although they are thought to be sexually mature (other sameaged individuals are known to breed). Two basic questions are why should an individual forego mating and why should that individual then help to rear other adults' young? In addition, it is important to study the behavioral and ecological factors that underlie dispersal polymorphisms evident in many social species (BEKOFF 1977a). Differential dispersal is closely related to the social biology of helping (BROWN 1969, 1974; BEKOFF 1981, 1983). In coyotes, the nature of winter food resources appears to be the major factor influencing social organization, dispersal patterns (BOWEN 1978, 1981; CAMENZIND 1978; BEKOFF and WELLS 1980), and helping.

The purpose of the present study was to analyze pup-rearing patterns, space use, and resource defense in two social units of free-ranging coyotes displaying contrasting social organizational patterns. One group has been a cohesive pack with helpers since at least 1977 whereas the other group has been a mated pair with no helpers (all offspring have dispersed between about 6 and 9 months of age). Because of ideal observation conditions, we have been able to follow identified individuals over long periods of time and also have been able to watch den sites. We analyzed (1) what helpers did, (2) the time budgeted by different individuals to den attendance, (3) the relationship between the number of adults attending a den(s) and (i) the number and percentage of pups surviving to 5-6 months of age, (ii) juvenile weight, and (iii) the frequency and amount of time that pups were left alone at den sites, (4) space use and movement patterns, and (5) territorial and food defense against intruding coyotes.

\section{Methods}

This research was conducted as part of an on-going study of the social ecology of coyotes living around Blacktail Butte in the Grand Teton National Park, about $20 \mathrm{~km}$ north of the town of Jackson, Wyoming, U.S.A. (BEKOFF and WELLS 1980, 1981; WELLS and BEKOFF 1981, 1982; details about the study area and methods can be found in these references and LIPETZ and BEKOFF 1982). Individuals and dens were observed using Celestron C90 or Bushnell spacemaster II spotting scopes; all measures of time were taken with digital stop watches. Observations were spoken into audio casette recorders and later transcribed. Univariate and multivariate statistical techniques were used as was an alpha level of $p<$ 
0.05. Because individuals and den sites were observed for different amounts of time, data were converted to percentages in some instances.

7 litters (4 for the pack: 1978-1981; 3 for the resident pair: 1978-1980) and associated den sites were observed for $340 \mathrm{~h}$. Pups were fitted with colored ear-tags when they were about 4-6 weeks of age. Litter size was assessed at this age, because it was not possible to do so before the altricial pups either emerged or were pulled from the den (also see MOEHLMAN 1981). Pups were handled minimally when they were tagged, and no pups were rejected by their parents (or helpers) after being placed back in the den. Dens were not directly disturbed again. When offspring for a given year were about 5-6 months of age, we attempted to trap (see WELLS and BEKOFF 1981 for details), weigh, and fit them with radiocollars (A VM LMW/E collars with cold temperature option).

Fig. 1: A pedigree for a pack of coyotes observed from 1977-1982 in the Grand Teton National Park, Wyoming, U.S.A. Young of each year that are not accounted for either dispersed or died before they were about 9 months of age. In late 1980 , the original pack mother disappeared (she returned to her former territory in late April 1982; see text) and a new, unrelated two-year old female joined the pack and mated with the original pack father. The father then disappeared shortly before pups were born in spring 1981. Male helper B21 (also referred to as B2-1 in text) mated with the new pack female in winter 1982; 6 pups were born $\left(4\right.$ 우, $\left.2 \delta^{\lambda}\right)$. In January 1982, all pack members except B21 and his mate dispersed. In April 1982, male helper ' 81 and female helper B36 rejoined the pack.

PACK PEDIGREE: $1977-1982$
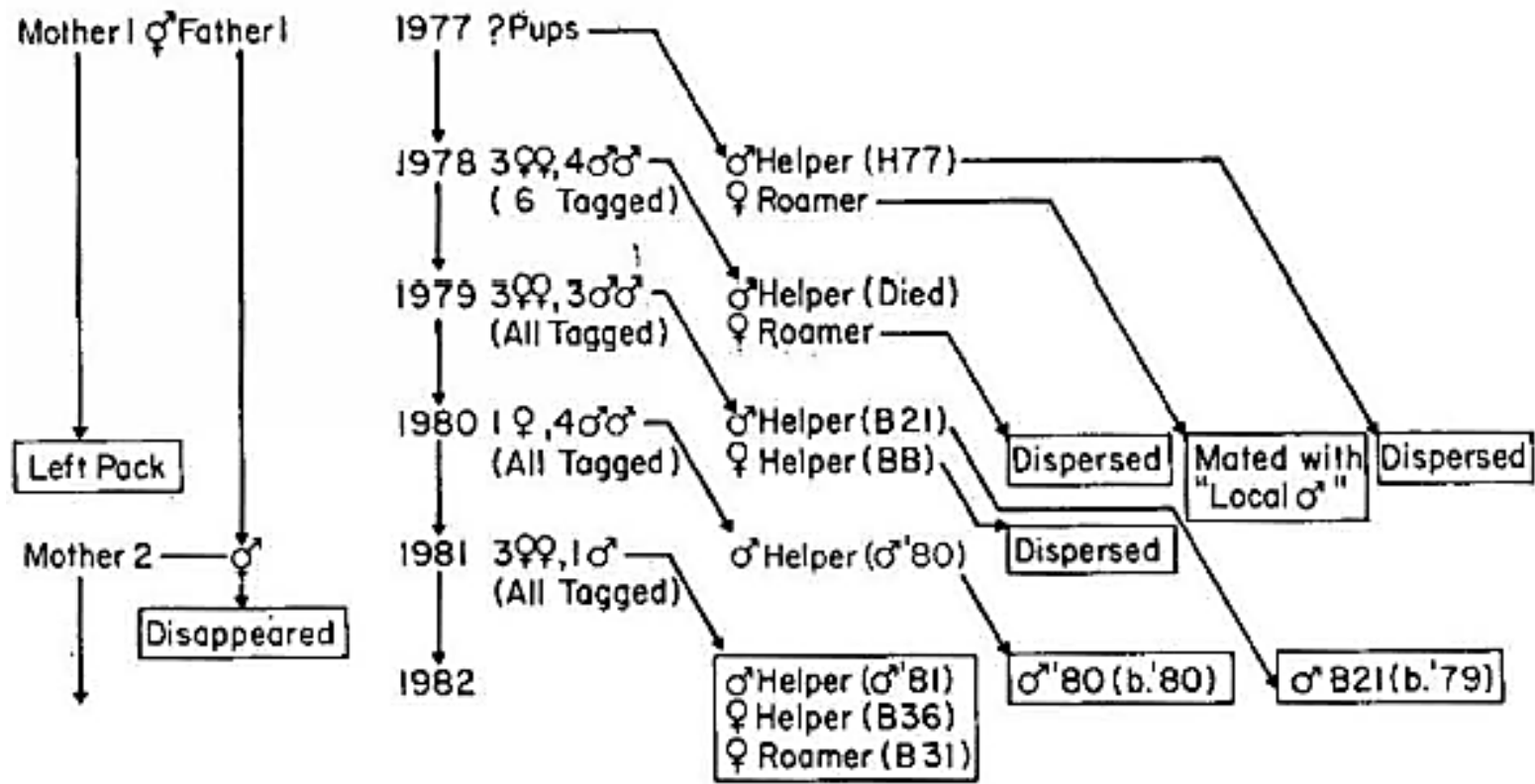

\section{Space Use}

Space use analyses were performed using a package of Hewlett Packard BASIC programs called SPACE-OUT (BEKOFF et al. 1982; BEKOFF and MECH 1982). The area of the convex polygon enclosed by $95 \%$ of all locations (closest to the geometric center of each individual's territory) for a specific coyote is presented here to a void over-estimating territory size due to infrequent long-distance forays (the same approach was taken by DUNN and GIPSON 1977, MICHENER 1979, 1981, ANDERSON 1982, and BOWEN 1982). In most cases, the $95 \%$ area was not much smaller than the total (100\%) territory size. 


\section{Pack Pedigree}

A pedigree for the pack is presented in Fig. 1. Five of $6(83 \%)$ helpers were males. In the fall of 1980, the first pack mother disappeared and a new, 2 year-old female joined the pack and mated with the pack male in 1981. The new pack mother was untagged and had not previously been observed. We feel confident that she was not related to any pack member. Shortly before his pups were born in April 1981, the pack father disappeared. In 1982, male helper B2-1 mated with the new pack female; 6 pups were born (4 +q,$>, 2 \hat{\jmath}$ ). In April 1982, the first pack mother returned to her former territory (see below). Throughout the course of this study, the same mated resident pair was observed.

\section{Results}

\section{Social Ecology; Food Resources, Reproduction, Dispersal, and Helping}

Annual food and reproductive cycles are outlined in Fig. 2. Coyotes on our study area depended mainly on human-hunter-killed elk (Cervus elaphus) carrion during winter months (BEKOFF and WELLS 1980, 1981; WELLS and BEKOFF 1982) and on small rodents [mainly voles (Microtus spp.) and Uinta ground squirrels (Spermophilus armatus)] during the rest of the year. Uinta ground squirrels were the major food resource from mid-April to mid-August; they hibernate during the rest of the year. Elk carrion availability around our study area was unevenly distributed for the past 5 winters. Where carrion has been abundant, clumped, and defendable, packs of coyotes have been observed; some, but not all, juveniles dispersed during the first year of life. When carrion was scarce and spread out geographically, resident mated pairs and solitary individuals predominated.

Fig. 2: Cycles of annual changes in food resources and reproductive behavior for coyotes living in the Grand Teton National Park, Wyoming, U.S.A.

\section{COYOTE SEASONS}

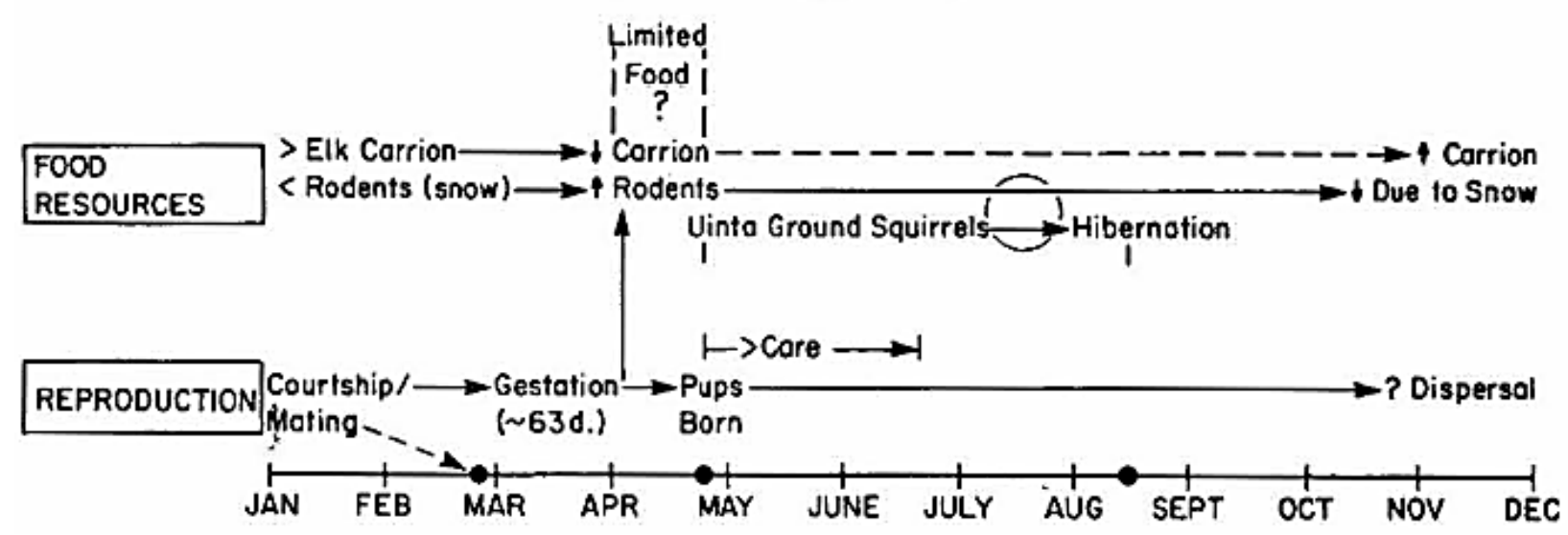

In order to present the functional relationship between sociality (group size) and winter food availability more rigorously, a regression analysis was performed $[x=$ number of helpers observed on or about January 15 of a given year; $y=$ number of hunter-killed elk within the territory or home range of known coyote groups (Grand Teton National Park, unpubl. data)]. The regression equation is $y=73.44+76.44 \mathrm{x}$ $\left(p<0.001, r^{2}=0.95, S_{b}=6.90\right)$. The correlation between the two variables was highly significant $(r=$ $+0.98, p<0.001)$. 
Coyotes on our study area began to engage in courtship activities in early January, and copulation usually took place in late February. After a gestation period of about 63 days, pups were born in late April in a subterranean den. Coyote pups are altricial and depend heavily on maternal care during early life. After pups emerged from the den at about 3-4 weeks of age, they still required care; they were weaned at about 6-7 weeks of age and became independent of parental food provisioning at about 4 months of age, at which time they began to hunt rodents successfully.

Fig. 3: Two dimensional plots of individual locations on territories occupied by pack parents (original mother and father, MOMPU and DADPU) and helpers ( $\delta$ helps $=\delta$ ' 77 and $B 2-1 P U=$ B21) when pups were present (April to July). For explanation of the different percentage (\%) areas (designated by different symbols), see text and BEKOFF et al. 1982. "O" (Fig. 3a) refers to the point from which observations were made.
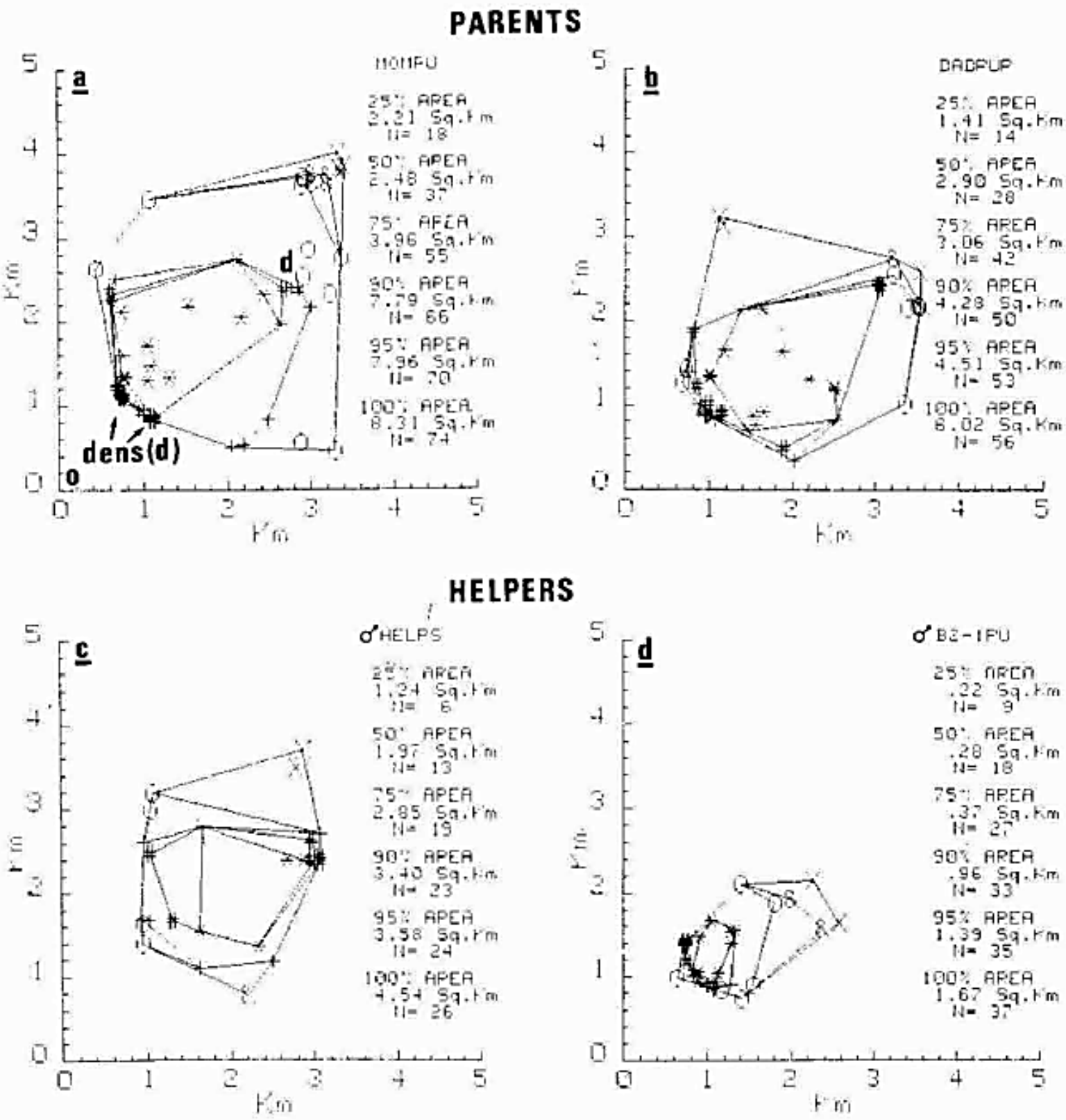
Dispersal of juveniles usually began in fall and continued throughout winter. Individuals who spent the first 10-11 months of life with their parents and older siblings and littermates typically did not disperse; they either became helpers, or remained on the periphery of their natal territory (as "roamers") and rarely interacted with their relatives (Fig. 1). Pack formation seems to be facilitated by non-dispersing young remaining in close proximity to parents and other group members over the first winter, as in communal birds. Strong social bonds are formed among all group members, aiding in the incorporation of nonreproducing offspring into the social group.

Fig. 4: Three-dimensional space use plots for the original pack mother, 1977-1980, (a) throughout the year (mom), (b) during fall (August to November; momfall), (c) during winter (December to March; momwinter), and (d) when pups were present (April to July; mompups). The numbers on top of some of the peaks (z-axis) refer to the percentage of total sightings of an individual within specific $200 \times 200-\mathrm{m}$ sections of its territory. " $n$ " is the sample size (number of sightings or radio-telemetry locations) and the number on the right of the slash $(I)$ with the asterisk $\left(^{*}\right)$ is the size of the $95 \%$ polygon (see text and Fig. 3 )
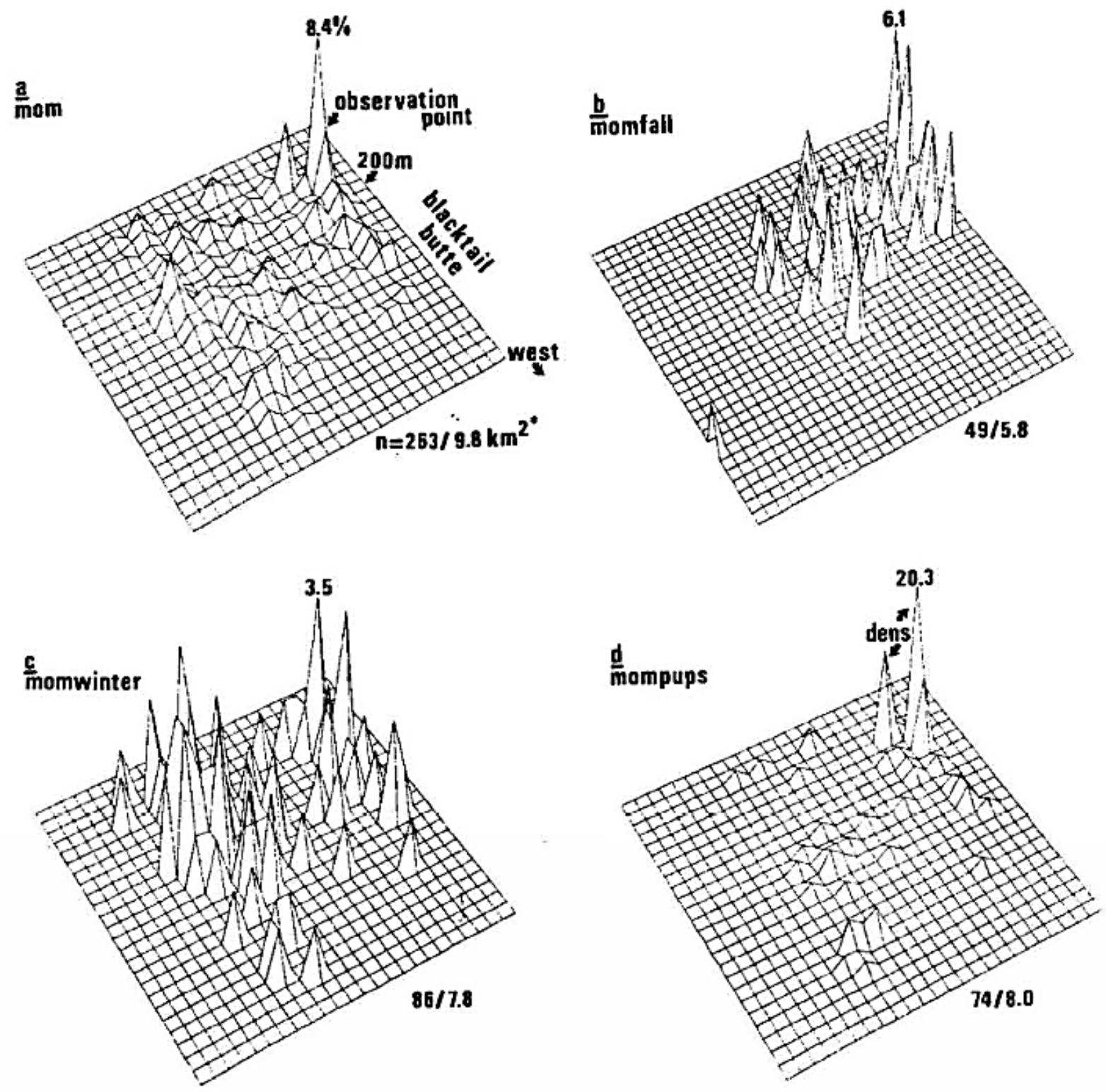
From about the beginning of April to the time at which Uinta ground squirrels emerged from hibernacula (late April), food resources may be limited, because carrion is depleted and snow cover rnay make it difficult for coyotes to catch small rodents. This time period coincided with the second half of pregnancy (and possibly with maternal lactation), and may possibly be a time when pregnant females and mothers became energetically stressed. Pack-living females may be better off energetically than females living only with their mates, based on analyses of activity patterns during winter (BEKOFF and WELLS 1981). However, the advantage for pack-living females may only be realized in periods of extreme food shortage. To date, the reproductive performance of both pack-living females and the female living only with her mate has been the same (see below).

\section{Mortality and Dispersal}

Of 16 identified yearlings (of known origin) who dispersed, at least $9(56 \%)$ were known to have died shortly after leaving their natal group (this is a minimum estimate because we only can determine the fate of dispersers if their radio-collars are returned). However, of 5 radio-collared non-dispersing juveniles, only 1 died during the first year of life.

\section{Full-siblings, Half-siblings, and Litter Size}

There were no differences in the treatment of full-siblings or half-siblings by helpers (Fig. 1), so data were combined. Litter size, determined at 4-6 weeks of age (see above) was not statistically different among the 7 groups [pack: $\bar{X}=5.5$ (standard deviation, $s d=1.3$ ); resident pair: $\bar{X}=5.3(s d=1.5) ; U=6.5, p>$ 0.05 ). Litter size was not significantly correlated with the number of adults in a group, nor with the number or percentage of pups surviving to 5-6 months of age.

\section{Feeding by Helpers and Parents}

Helpers did not provide much direct care to young pups, nor did they provide much food to the pack mother. Only 1 helper ( $\mathrm{H} 77$ ) was observed to regurgitate food to his mother (3 times); he fed his younger siblings only once. Male helper B2-1 regurgitated food 4 times to his full-siblings in 1980 and fed his halfsiblings (1981) on 9 occasions. Only 1 helper $(\mathrm{H} 77)$ chased intruding coyotes away from a den site (2 times); 3 helpers barked at MICHAEL WELLS when he approached den sites (H77: 5 times; B2-1: 7 times; female BB: 2 times). Helpers rarely played with pups and never actively partook in den moves. The involvement of helpers in den attendance (den-sitting) is discussed below.

Mothers were observed to nurse pups 19 times after young emerged from dens. On only 4 occasions did mothers provide solid food to pups. Fathers were observed to feed pups only once and to feed their mates twice (regurgitations). Despite optimal observation conditions, feeding was difficult to document; undoubtedly our data are underestimates.

\section{Space Use}

\section{(a) Frequency Analyses}

Movement patterns and space use (during daylight hours) were studied throughout the year; seasonal comparisons were made to determine if there were detectable changes in the use of space when pups were present. Patterns of space use when pups were present are shown in Fig. 3 for the pack mated pair

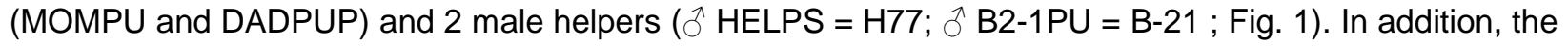
sizes of 6 frequency-use convex polygons are listed (25\%,50\%,75\%,90\%, 95\%, 100\%); the geometric center $(\overline{\mathrm{x}}, \overline{\mathrm{y}})$ was calculated for each individual and each polygon represents the area encompassed 
(outward from the geometric center) by $25 \%, 50 \%, 75 \%, 90 \%$, and $95 \%$ of the total locations as well as the area defined by all (100\%) locations.

Fig. 5: Three-dimensional space use plots for male helper B2-1 (or B21), 1979-1981, (a) during winter and (b) when pups were present. See Fig. 4 for labeling details.
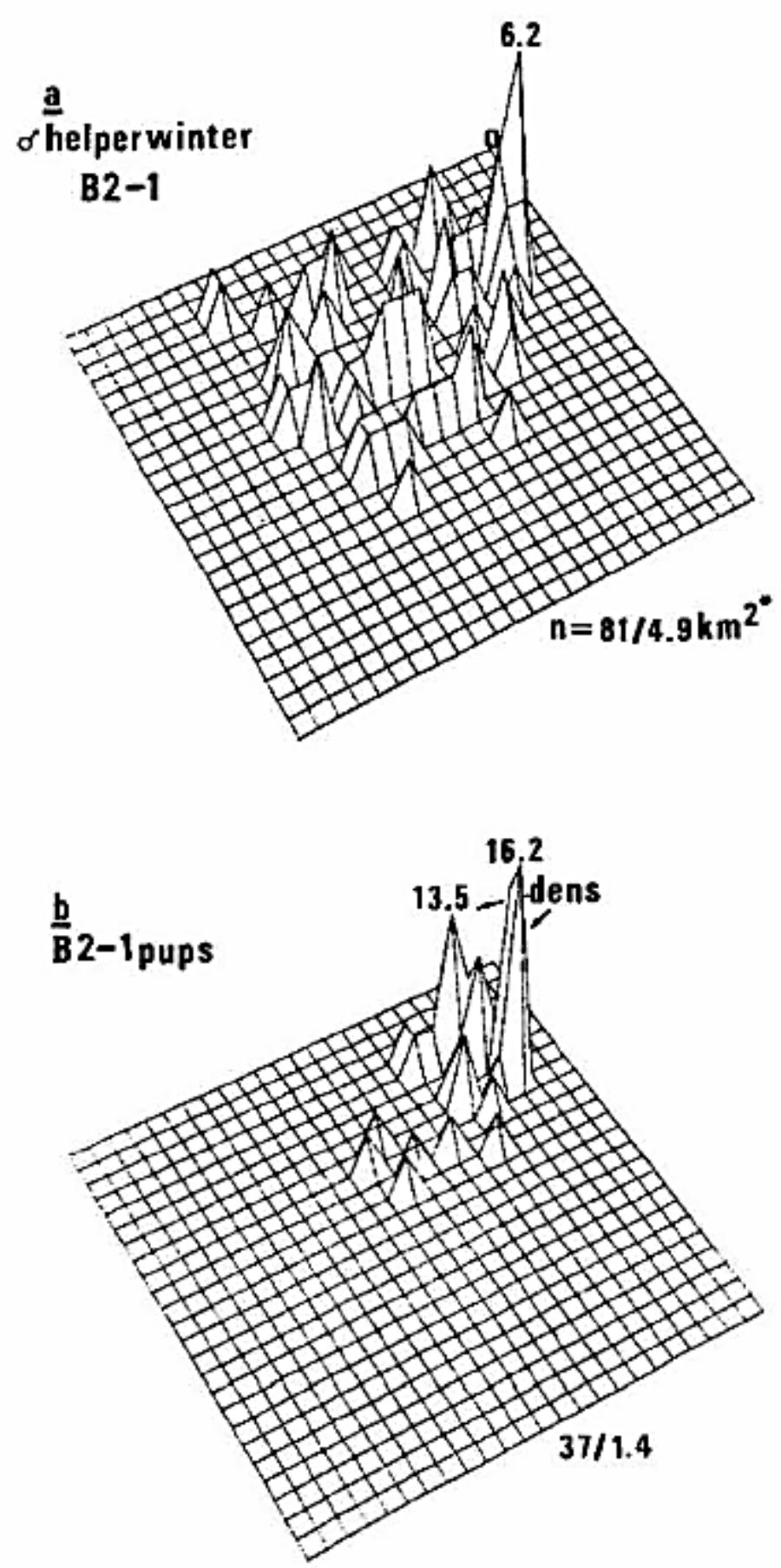
More detailed analyses of space use are pictured in the 3-dimensional displays (Figs. 4 and 5). Note, for example, that the pack mother (Fig. 4) showed almost a 6-fold increase in the relative frequency with which she was observed within the same $200 \times 200-\mathrm{m}$ section when pups were around (Fig. 4d, mompups; $20.3 \%$ where dens were located) as compared to the immediately preceding winter months (Fig. 4c, momwinter; 3.5\%). There was little difference in the size of the 95\% frequency-use polygon (momwinter; $7.8 \mathrm{~km}^{2}$; mompups: $8.0 \mathrm{~km}^{2}$ ). Similar changes in the use of space were noted for the pack father and male helper B2-1 (Figs. 5a and b). Furthermore, the area in which B2-1 was observed on 95\% of all sightings was 3.5 times larger during winter (Fig. $5 \mathrm{a} ; 4.9 \mathrm{~km}^{2}$ ) than when pups were present (Fig. $5 \mathrm{~b} ; 1.4 \mathrm{~km}^{2}$ ). Male helper ' $77(\mathrm{H} 77)$ also showed changes in space use when comparing his movement patterns during winter with the period when pups were around, but he was observed proportionately less (7.7\%) around den sites than the pack mother, pack father, or B2-1.

Fig. 6: The percentage of time (total time individual was observed at active den sites/total time individual was observed anywhere) that individual coyotes budgeted to the attendance. Alone $=$ time individual was at den alone/total time individual was at den. There was no significant difference in mean litter size (determined at 46 weeks of age; see text) between the pack and resident pair. Pup survival was not significantly correlated with the number of adults attending a den(s) (see text and Fig. 9). See Fig. 1 for individual identification.
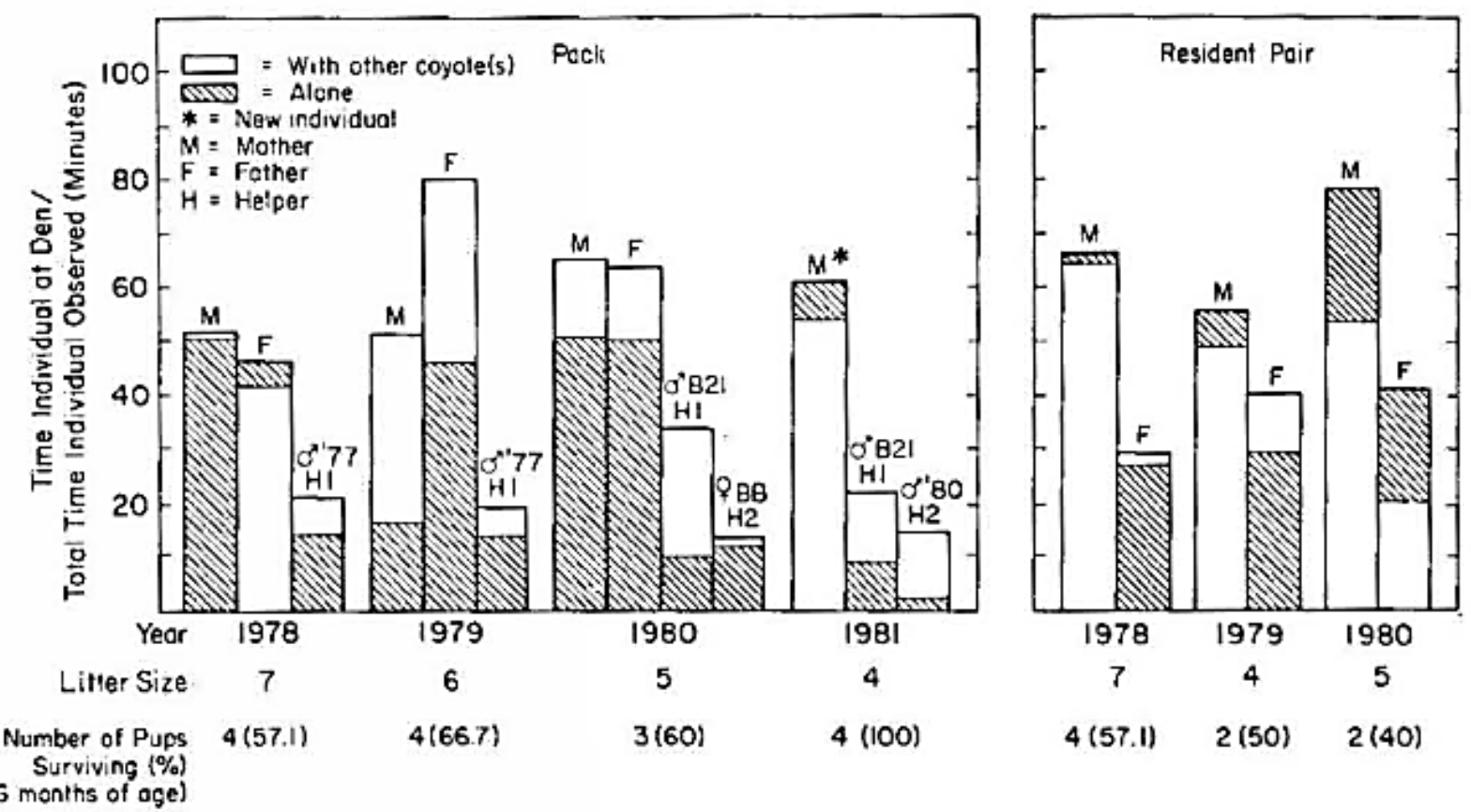

(5-6 months of age)

\section{(b) Den Attendance Time Budgets}

The amount of time that individuals were observed at den sites divided by the total amount of time that they were observed anywhere was calculated to represent the proportion of time that individuals budgeted to den attendance (Fig. 6). All individuals were observed around active den sites both in association with other adult group members and alone. The two pack mothers $(1978-1980 ; 1981)$ allocated approximately the same proportion of time to den attendance (1978-1980: 57.0\%; 1981: 53\%; $t_{\text {sample }}=-0.45, p>0.05$; see SOKAL and ROHLF 1981, p. 231 for method used to compare a single observation with the mean of a sample). There also was no difference between pack mothers and the resident pair female $\left[X^{2}=0.43, p>0.05\right.$; Kruskal-Wallis one-way analysis of variance with corrections for ties (hereafter, all $X^{2}$ values refer to this statistical test)]. Although the resident pair mother was alone an average of $65.8 \%$ of the time that she was at the den, and the first pack mother was alone only an 
average of $39.4 \%$ of the time she was at the den, the difference in these 2 percentages was not statistically significant $\left(X^{2}=1.19, \mathrm{p}>0.05\right)$. Furthermore, there was no difference between the first and second pack mothers $\left(\mathrm{t}_{\text {sample }}=0.90, \mathrm{p}>0.05\right)$.

The pack father (1978-1980) also spent a lot of time at den sites and showed changes in space use patterns (Fig. 6). He ( $\overline{\mathrm{X}}=62.4 \%)$ spent significantly more time proportionately around den sites than did the resident pair male $\left(\overline{\mathrm{X}}=30.1 \% ; x^{2}=3.86 ; \mathrm{p}<0.05\right)$ and proportionately more time alone (pack father: $\overline{\mathrm{X}}=48.0 \%$; resident pair father: $\left.\overline{\mathrm{X}}=32.8 \% ; \chi^{2}=3.86, \mathrm{p}<0.05\right)$. There was no significant difference between the pack mother and father with respect to the proportion of time spent around den sites $\left(X^{2}=\right.$ $0.34, p>0.05)$. The resident pair female spent a significantly greater percentage of time around dens than did her mate $\left(X^{2}=4.23, \mathrm{p}<0.05\right)$.

Helpers (male H77, male B2-1, female BB, and male '80) were observed at den sites an average of about $21 \%$ of the total time that they were observed anywhere, and in each year, a helper(s) was present for a significantly smaller percentage of time than either parent. (Roamers were not observed around dens.) The same trend was found for the percentage of time that helpers were observed alone at dens. Multiple regression analysis showed that the amount of time that helpers spent at dens could not be predicted by either (1) the number of adults present, (2) litter size, (3) the proportion of time that mothers devoted to den attendance, or (4) the percentage of time that the father devoted to den-sitting $(F=52.56, p=0.09)$.

Fig. 7: The percentage of time (total time individual was observed at active den sites/total time den was attended) that individuals devoted to the total group effort involved in den attendance (see Results, 5c). See Fig. 1 for individual identification.
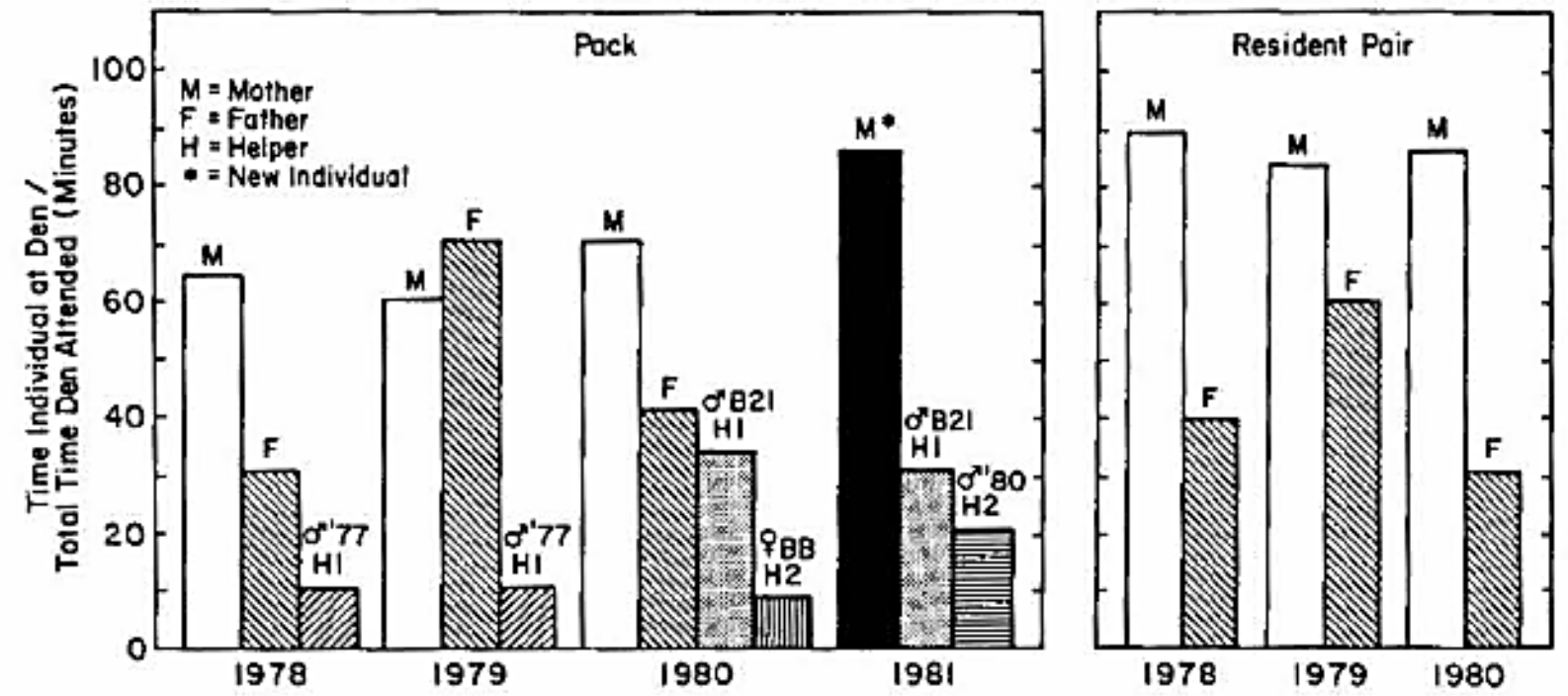

(c) Individual Investments to Den Attendance

We also calculated the time that individuals were observed at dens given that dens were attended (Fig. 7). This measurement reflects the relative proportion of time that individuals devoted to the total group effort involved in den attendance. The pack mother from 1978-1980 showed little variation from year-toyear $[\bar{X}=65.0 \%(s d=4.97)$, coefficient of variation $(C V=s d / \bar{X})=0.08)]$ as did the resident pair female $[(\bar{X}$ $=86.4 \%$ (sd $=3.19), \mathrm{CV}=0.04]$. Whereas the percentage of time budgeted to den attendance was about the same for the original pack mother (1978-1980) and the resident pair female (Fig. 6; see above), the pack female contributed significantly less to the pack's den attendance effort than did the resident pair 
mother to her group's effort $\left(X^{2}=3.86, \mathrm{p}<0.05\right)$. Although the new pack mother $(1981)$ contributed about $22 \%$ more to the group den attendance effort, the difference between her contribution and the original pack mother was not statistically significant $\left(t_{\text {sample }}=3.46, p>0.05\right)$.

Pack and resident pair fathers contributed about the same percentage of time to the den attendance effort of their respective groups (pack male: $\overline{\mathrm{X}}=47.6 \%$; resident pair male: $\overline{\mathrm{X}}=42.9 \% ; x^{2}=0.51, \mathrm{p}>0.05$ ). There was no significant difference between the pack male and female from 1978-1980 $\left(X^{2}=0.75, p>\right.$ 0.05). The resident pair mother contributed significantly more to den attendance than did her mate $\left(X^{2}=\right.$ $4.23, p<0.05)$. All helpers contributed less than all parents $(\bar{X}$ percentage $=19.51 \%$, $s d=10.63)$; male B2-1 contributed more than other helpers $(\bar{X}=32.2 \%, s d=1.93)$ but less than his parents.

\section{Pack Adult Association at Den Sites}

Associations among adults at dens were analyzed with respect to the amount of the time that each individual was observed at den sites with another group member. Of the total time that the first pack mother was observed at dens, she was there with her mate $45.7 \%$ of the time and was observed in association with a helper(s) for much smaller proportions of time (range $=4.2-15.2 \%$ ). Similar trends were observed for the pack male [at den with mate $60.2 \%$ and with a helper(s) between 5.1 and 13.8\%]. Because pack parents spent more time at dens than did any of their offspring, helpers were observed at den sites more in association with a parent(s) than with an older sibling(s) or with a littermate(s). We found no evidence for any synchronization for departure from, or arrival at, den sites among adults (also see YOUNG and DOBYNS 1937; ANDELT et al. 1979 and ALTHOFF and GIPSON 1981).

Fig. 8: The frequency pups were left alone, the percentage of time that pups were left alone, and the mean number of min they were left alone each time they were left unattended (see text).

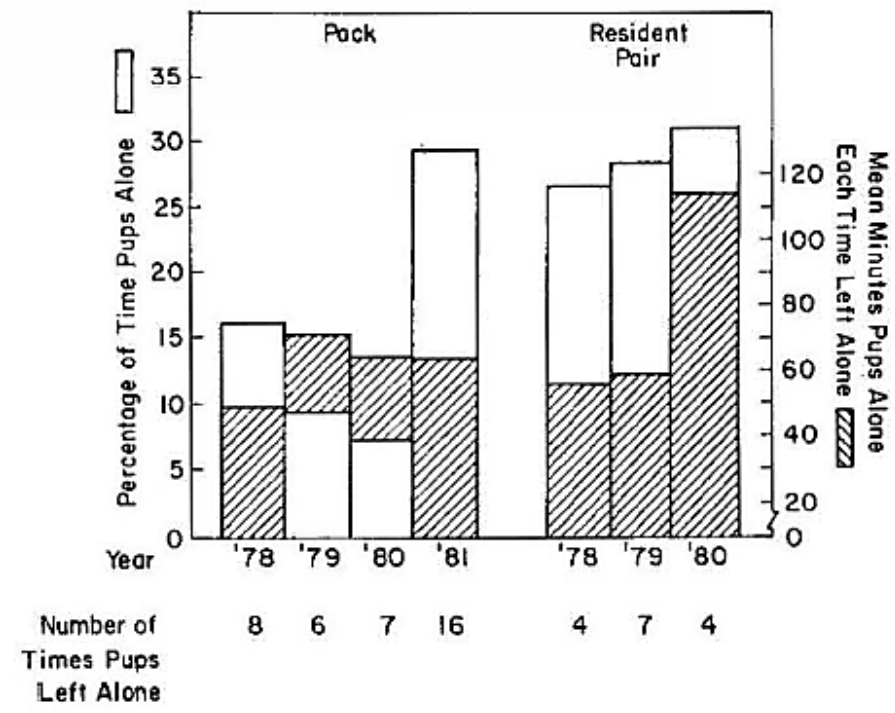

\section{Helper Effects}

(a) Frequency and Time Pups were Left Unattended

Pups were left alone about the same number of times when there were 2 parents associated with den sites (Fig. 8; 1978-1980, $X^{2}=1.8, p>0.05$ ). However, in 1981, when there was only 1 parent in the pack, 
pups were left unattended significantly more frequently than when there were 2 parents in the pack ( $\mathrm{t}_{\text {sample }}$ $=7.89, \mathrm{p}<0.02)$.

The mean number of minutes that pups were left alone each time that they were left unattended in a given year was not significantly different when comparing the pack with the resident pair [pack: $\overline{\mathrm{X}}=62.2$ ( $s d=11.9)$; resident pair: $\bar{X}=77.1$ ( $\left.s d=33.0) ; \chi^{2}=0.05, p>0.05\right]$. The resident pair showed greater variability in this measure $\left(\mathrm{CV}_{\text {resident pair }}=0.43 ; \mathrm{CV}_{\text {pack }}=0.19\right)$. In 1980 , resident pair pups were left alone for an average of almost $2 \mathrm{~h}$ each time they were left unattended (Fig. 8).

When 2 parents were present in the pack (1978-1980), the mean percentage of time that pups were left alone (min pups alone/min den observed) was significantly less than the mean proportion of time that resident pair pups were left unattended (Fig. 8; $x^{2}=3.86, \mathrm{p}<0.05$ ). However, when only 1 parent (mother) was present in the pack (1981), the percentage of time that pups were left alone increased significantly compared to the years when 2 pack parents were present $\left(t_{\text {sample }}=6.9, p<0.05\right)$, and closely approximated similar data collected for the resident pair. As the amount of time that parents budgeted to den attendance decreased, the percentage of time that pups were left alone increased $\left(r_{s}=-0.77, p=\right.$ 0.04). There was no significant correlation between the amount of time that helpers budgeted to den attendance and the proportion of time that pups were left unattended. A more detailed discriminant function analysis in which the pack and resident pair were compared indicated that the percentage of time that pups were left alone was the most important variable separating the 2 groups; there was no overlap between them on the discriminant axis $\left[X^{2}=15.24, p=0.009, D^{2}\right.$ (distance between the group centroids (means) $=35.95]$.

(b) Relationships Between Number of Adults and Pup Survival, Survivorship, Weight, and Time Left Alone

As mentioned above, litter size was assessed when pups were about 4-6 weeks of age. The number of pups surviving and the weight of juveniles was determined when offspring were 5-6 months of age. There were no significant correlations $(p>0.05)$ between litter size and (1) number of adults present $\left(r_{s}=\right.$ $+0.02)$, (2) number of pups surviving to 5-6 months of age $\left(r_{s}=+0.54\right)$, or (3) percentage of pups surviving $\left(r_{s}=-0.07\right)$. Litter size was about the same for both the pack and resident pair (see above).

A non-significant relationship was found between the number of adults attending a den(s) and the number of pups surviving to 5-6 months of age (Fig. 9a); a positive trend is obvious. The regression coefficient (0.46), or slope of the regression line (indicating the increase in the number of pups surviving as a function of the number of adults attending dens), was nonsignificant. The coefficient of determination, $r^{2}, a$ measure of the proportion of the variation of one variable that is determined by variation of the other variable, was very small (0.13), suggesting that factors other than number of adults present influenced pup survival. Data in Fig. 9a also show that a pair of coyotes was able to raise 2.7 pups to 5-6 months of age and that each helper increased pup survival by a factor of 0.46 . Multiple regression analysis indicated that the number of pups surviving could not -be predicted by the number of adults present at dens or by the proportion of time budgeted to den attendance by either mothers or fathers $(F=1.78, p=0.25)$.

The relationship between the number of adults attending dens and the percentage of pups that survived to 5-6 months of age is presented in Fig. 9b. The regression coefficient (10.50) was non-significant and $\mathrm{r}^{2}$ was very small, but there was a significant positive correlation $\left(r_{s}=+0.72, p=0.03\right)$ between the two variables.

As mentioned above, helpers did not provide much food to pups. A nonsignificant relationship was found between the number of adults attending den sites and the weight of juvenile survivors (Fig. 10a). Mean 
weight for pack juveniles $(n=10)$ was $9.0 \mathrm{~kg}(\mathrm{sd}=1.3)$ while resident pair juveniles averaged $8.1 \mathrm{~kg}(\mathrm{sd}=$ 1.2); the difference was non-significant $(U=34, p>0.05)$.

Fig. 9: Regression and correlational analyses between the number of adult coyotes present at dens (number of helpers = number of adults - 2) and the number (a) and percentage (b) of pups surviving until at least 5-6 months of age. $\mathrm{r}^{2}=$ coefficient of determination, $\mathrm{SE}_{\mathrm{b}}=$ standard error of the regression coefficient (slope), $\mathrm{r}_{\mathrm{s}}$ $=$ Spearman's coefficient of rank correlation.

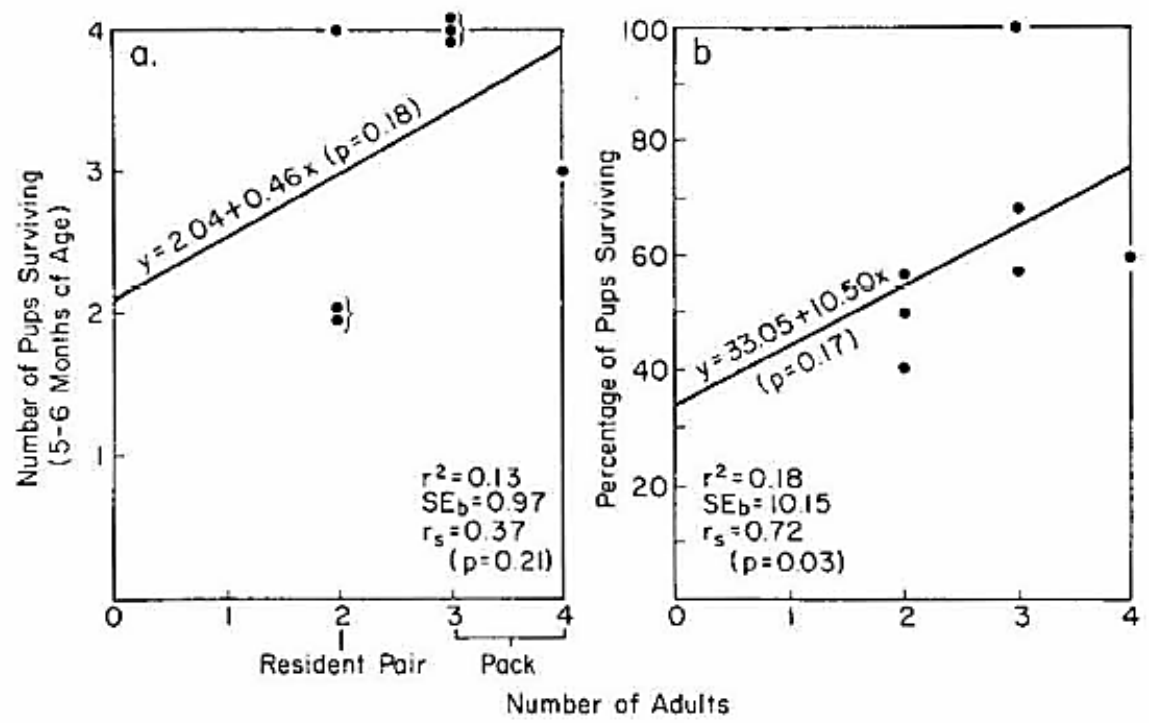

Fig. 10: Regression and correlational analyses between the number of adult coyotes present at dens and offspring weight at 5-6 months of age (a) and the amount of time pups were alone each time they were left unattended, expressed as a percentage of the total time that dens were observed (see Fig. 9 legend for definitions of $r^{2}, S E_{b}$, and $r_{s}$ )

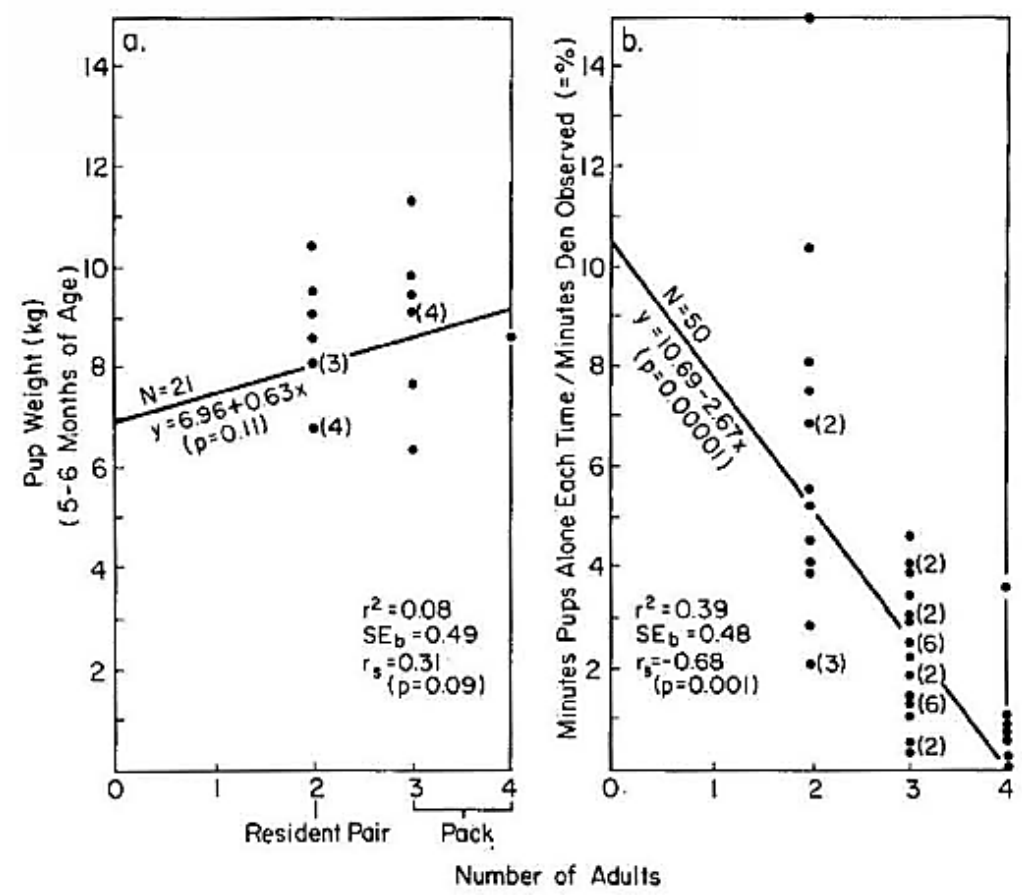


A highly significant negative relationship was found between the number of adults attending dens and the amount of time pups spent alone each time they were left unattended, expressed as a percentage of the total time that dens were observed (Fig.10b).

\section{Den Movements}

27 den moves were observed in the pack. The mean distance of each movement was about $1340 \mathrm{~m}$ (sd $=$ 1090). The resident pair was observed at 8 den sites (mean distance moved $=1450 \mathrm{~m}, \mathrm{sd}=614$ ). There were no obvious reasons for the majority of the den moves or for the direction or distance that parents chose to move. Six (17\%) moves may have occurred because of observers' disturbance, but after the individuals were settled into a new area, there were no notable changes in behavior when compared to observations made at previous den sites.

Helpers and fathers never were observed to move pups. Mothers either carried or led pups to new areas. In one move of approximately $1700 \mathrm{~m}$, the pack mother (1978) made 7 round-trips over a period of about $16 \mathrm{~h}$ (about $24 \mathrm{~km}$ total distance), carrying 1 pup each time to the new den site.

\section{Pack Defense Against Intruding Non-Pack Coyotes}

Only pack members actively defended a territory; resident mated pairs and solitary individuals were not territorial. Non-pack coyotes were observed to intrude into the pack's territory only 7 times when pups were present. The parents chased the intruder 5 (71\%) times (mother: 2 times; father: 3 times). Only 1 helper (male H77) chased an intruder (2 times).

During winter months (December to April), we observed 48 pack-intruder encounters. 83\% (40/48) involved a lone intruder. A single pack member engaged in 15 interactions and 2, 3, 4, and 5 pack members partook in 15, 10, 7, and 1 encounters, respectively. Pack members "won" a significantly greater proportion of interactions $(n=36,75 \%)$ than did intruders $\left(t_{s}=3.14, p<0.01\right)$. A pack "win" was indicated only if the pack member(s) involved in the encounter was able to drive the intruder(s) off of the territory, whereas an intruder "win" was scored if the intruder was not chased off of the pack's territory. Therefore, "winning" was biased towards intruders.

The mean number of pack individuals involved in successful encounters with intruders was 2.6. Significantly fewer pack members $(\bar{X}=1.3 ; U=39.5, p<0.02)$ were involved in pack losses. Of the 15 interactions involving a single pack member, 10 (67\%) were lost [10/12 (83\%) pack losses involved a lone pack member]; on only 5 occasions did a single pack member successfully drive off an intruder.

All pack members partook in territorial and food (elk carrion) defense during winter. At least 1 parent was involved in 31 (65\%) encounters and at least 1 helper was observed in 37 (77\%) interactions. Helpers initiated $29 / 48(60 \%)$ of all encounters and $29 / 37(78 \%)$ of the interactions in which they partook.

(a) Pack Initiated Defense and Intruder Density

Pack members initiated 34 (71\%) of the encounters with intruders [the difference between the percentage of interactions initiated by pack members and intruders was significant $\left.\left(t_{s}=2.73, p<0.01\right)\right]$. The frequency of pack initiated encounters was directly related to the number of intruders present at any one time on the pack's winter territory (approximately $8 \mathrm{~km}^{2}$ ). When there were 1,2 , or 3 non-group coyotes present, pack members initiated 17/17 (100\%) interactions. When 4 intruding coyotes were present, pack members initiated $4 / 6(66.7 \%)$ encounters, when there were 5 non-group coyotes present, the pack initiated 10/17 (59\%) interactions, and when 9 intruders were present, the pack initiated only 2/7 (29\%) encounters. The regression equation for the relationship between the number of intruders present on the 
pack's territory $(x)$ and the percentage of encounters (total number of interactions $\geqq 4$ ) initiated by pack members $(y)$ is $y=129.40-11.26 x\left[r^{2}=0.88, r=-0.94(p<0.01)\right]$.

\section{Discussion}

\section{Behavioral Ecology of Helping}

Coyotes live in different types of social groups ranging from single individuals, to mated pairs, to packs. Pack formation appears to be an adaptation for the defense of food rather than for its acquisition (BOWEN 1978, 1981; CAMENZIND 1978; BEKOFF and WELLS 1980). Packs typically consist of a mated pair and their non-dispersing, non-breeding offspring, although nonrelated individuals may become incorporated into an already existing pack (for example, the new pack mother in 1981). Coyote helpers did not breed while they remained on their natal territory. However, same-aged coyotes are known to be reproductively active (KENNELLY and JOHNS 1976). Depending on the stability of the mated pair from year-to-year, pack young may vary in genetic relatedness.

On our study area, the major winter food resource, human-hunter-killed elk carrion, has been asymmetrically distributed (see BEKOFF and WELLS 1980 for details; the same trend has been evident since winter 1977-1978). We found a highly significant relationship between sociality (group size) and the abundance of elk carrion during the winter $(r=+0.98)$. WEAVER (1979) also found that elk carrion greatly influenced coyotes in the Jackson Hole area; coyotes were most numerous where elk carrion was most abundant $(r=+0.84, p<0.05)$. Available data strongly indicate that winter food supply is the major ecological variable influencing juvenile dispersal and coyote social organization (BOWEN 1978, 1981; BEKOFF and WELLS 1980; for a discussion of possible behavioral variables affecting dispersal see BEKOFF 1977a and GAINES and McGLENAGHAN 1980).

Food availability also can affect the social organization and behavior of other canids (MACDONALD 1979; VON SCHANTZ 1981a, b; HARRINGTON et al. subm.). VON SCHANTZ found that in red foxes (Vulpes vulpes) living in Sweden, non-breeding group members occurred mainly during years of high food abundance, but that their presence could increase competition for food. MOEHLMAN (1979), however, reported that the presence of blackbacked jackal (C. mesomelas) helpers was independent of the density of food resources.

For coyotes on our study area, the presence of non-breeding helpers and roamers between 1977 and 1981 did not result in increased food competition, probably because food was sufficiently abundant. However, during January 1982, deep snow blanketed the study area and elk carrion and rodents were not as readily accessible to pack members as in previous years, and all pack young except B2-1 (and the new mother) disappeared. In April 1982, when food was more abundant, male helper '81 and female helper B36 rejoined the pack and spent a lot of time around the new den established by B2-1 and his mate, the new pack female. Surprisingly, the first pack female also returned to her old territory, but she spent little time around the den site and interacted only with B2-1, her son.

\section{Helper Roles: Food Provisioning, Den-Sitting, and Defence}

Two major contributions that helpers could potentially make include feeding pups or parents and guarding the den site. Our data indicate that coyote helpers do not play a significant role in food provisioning, in contrast to African wild dogs (Lycaon pictus; MALCOLM 1979; MALCOLM and MARTEN 1982) or blackbacked jackals (MOEHLMAN 1979). MOEHLMAN reported that the percentage of observed regurgitations by helpers to blackbacked jackal pups varied from $18-32 \%$ within families (sample size was not given). She concluded that the critical factor in pup survival was the number of provisioning adults that could capture grass rats (Arvicanthus niloticus) and make them accessible to the pups. 
Helpers' presence did not affect the proportion of time that the pack mothers allocated to den attendance. When there was only 1 parent in the pack (mother, 1981), pups were left alone significantly more frequently, indicating that helpers' presence did not override the absence of a parent. Also, when the pack contained both parents and helpers (1978-1980), pups were left alone for a significantly lesser percentage of time than when only the mother was present. When both parents were present in both groups, the most important variable discriminating between the pack and the resident pair was the percentage of time that pups were left alone (pack < resident pair).

The more time that pups were left alone, the more susceptible they were to harassment and possible predation by intruding coyotes and other predators (for discussions of pup vulnerability to predation in other canids see SAGGESE and TULLAR 1974, GARROTT and EBERHARDT 1982, and MALCOLM and MARTEN 1982). While intraspecific killing of coyote pups appears to occur only rarely, it was observed twice by CAMENZJND (1978); on both occasions the dens were unattended. The mere presence of parents and helpers at den sites may be sufficient to ward off any danger.

Den-sitting also has been observed in other carnivores (KRUUK 1972; ROOD 1978; LAMPRECHT 1979; MALCOLM 1979; MOEHLMAN 1979, 1982; OWENS and OWENS 1979; HARRINGTON and MECH 1982; MALCOLM and MARTEN 1982). ROOD noted that helpers protected young dwarf mongooses (Helogale parvula) from various ground predators such as Cape hunting dogs by chasing them and performing alarm calls. HARRINGTON and MECH (1982) observed that gray wolf (C. lupus) pups were left alone less when there was an increase in the number of adults and yearlings in packs. In brown hyenas (Hyaena brunnea Thunberg), protection of young seems to be one of the most important functions of communal denning (OWENS and OWENS 1979).

Coyote helpers, along with parents (including the new pack female), also partook in active group defense of food and territory, especially during winter months (for reviews of group territoriality see BROWN 1969, 1982b). When pack members were successful in chasing an intruding non-group coyote off of their territory or away from carrion, an average of more than 2 pack members was involved in the encounter; the importance of helper's presence is obvious. Another advantage associated with the presence of individuals other than parents is that active defense can be shared and more area can be covered during daily movements.

The initiation of defense of territory by pack members was negatively correlated with the number of intruders present at any one time on the pack's territory (intruder density). LAMPRECHT (1978) suggested that in some carnivores the amount of defense should be correlated negatively with the physical strength and numbers of aggressive competitors (for comparative data on birds see MYERS et al. 1979 and EWALD et al. 1980).

\section{Helper Effects}

The presence of coyote helpers did not significantly increase the number of pups that were observed to survive to 5-6 months of age, but there was a positive trend $\left(r_{s}=+0.37\right)$ between number of adults attending a den and pup survival. Helpers' presence did not negatively affect pup survival by increasing competition for food, for example. The average probability of an individual pup surviving was positively and significantly correlated with the number of adults attending den sites. Although helpers' presence was strongly associated with high quality winter habitat, even these two variables working in conjunction did not significantly increase pack pup survival when compared to that of the resident pair pups (see BROWN and BALDA 1977). Helpers' presence also did not have a significant effect on the weight of juvenile survivors. 
Two coyote parents reared an average of 2.7 pups to 5-6 months of age, and each helper added only 0.46 pups. Therefore, it appears that it would be genetically advantageous for an individual coyote to breed as soon as possible and to rear its own pups. It is important to stress that we found that litter size (at 4-6 weeks of age) was not significantly correlated with number of adults or with either the number or percentage of pups surviving.

Few field data for other carnivores are available with which we can directly compare our results. (For comparative information on birds see BROWN 1978, 1980, 1982 a; STALLCUP and WOOLFENDEN 1978; STACEY 1979; REYER 1980; EMLEN 1981; LIGON 1981; ROWLEY 1981; BROWN et al. 1982; and references therein.) VON SCHANTZ (1981b) found that the presence of red fox helpers did not increase group reproductive output and he suggested that if food was scarce, helpers' presence could reduce the breeding foxes' reproductive success. VON SCHANTZ also did not find a significant relationship between litter size and group size. HARRINGTON et al. (subm.) found that ecological conditions (habitat quality) exerted a strong influence on the inter-relationships among pack size, litter size, pup weight, and pup survival in wolves. Where prey were abundant and the wolf population was increasing, positive (although not all statistically significant) correlations were found between pack size and litter size, pack size and pup weight, and pack size and number of surviving pups. However, where prey were scarce and the wolf population was declining, negative correlations were found between pack size and litter size, pack size and pup weight, and pack size and number of surviving pups (for detailed analyses see their paper). HARRINGTON et al. (subm.) concluded that there was a dynamic relationship between food resources and helping, and that prey availability affected the overall effectiveness and the individual expression of helping behavior.

MOEHLMAN (1981) reported a significant correlation between both the number $\left(r_{s}=+0.58, n=10, p<\right.$ $0.05, r^{2}=0.29$; the critical value of $r_{s}$ for $p<0.05, n=10$, is 0.56$)$ and percentage $\left(r_{s}=+0.88, p<0.01\right)$ of blackbacked jackal pups surviving to 3.5 months of age and the number of adults attending a den(s). With the addition of 7 more data points, a higher correlation was found between the number of adults associated with a den(s) and the number of surviving blackbacked jackal pups (MOEHLMAN 1982; $r_{\mathrm{s}}=$ $+0.85, \mathrm{n}=17, \mathrm{p}<0.01$ ). However, MOEHLMAN also reported significant correlations between litter size (determined at 3 weeks of age) and number of adults present $\left(r_{s}=+0.83, p<0.01\right)$ and litter size and number of pups counted at 3.5 months of age $\left(r_{s}=+0.68, p<0.05\right)$. Therefore, regardless of the magnitude of $r_{s}$, it is not possible to determine exactly how helpers' presence is translated into increased pup survival. An increase in the number of pups surviving may be due either to direct or indirect postnatal care or may be the result of larger litters for females living in groups with helpers (MONTGOMERIE 1981). Nonetheless, the presence of adults other than parents at den sites was associated with increased pup survival, in agreement with the trend detected in the present study.

MALCOLM (1979) also found a (marginally) significant correlation between the number of adults attending a den(s) and the number of African wild dogs reared to 1 year of age, excluding total breeding failures $\left(r_{s}=+0.85, n=6, p<0.05, r^{2}=0.81\right.$; the critical value of $r_{s}$ for $p<0.05, n=6$, is 0.83 ; for all cases, including total breeding failures, $n=17, r_{s}=+0.38, p>0.05, r^{2}=0.20$; see MALCOLM and MARTEN 1982 for details).

While some available data for canids suggest positive trends between the number of adults attending a den (number of helpers = number of adults -2 ) and pup survival (regardless of the value of the correlation coefficient, some benefit is associated with helpers' presence), the ways in which helpers' effects are realized are not clear. Furthermore, there are no statistically significant differences among the regression coefficients (the slopes of the regression lines representing the increase in the number of surviving young associated with an increase in the number of adults attending dens) for published data available at this time for coyotes, Cape hunting dogs, or blackbacked jackals (unpubl. analysis: $S_{\text {sample }}=5.23<F_{(0.05)}=$ 
21.45; SOKAL and ROHLF 1981). The low values of $r^{2}$ also indicate that factors other than the number of adults attending dens must be considered. Future research and increased sample size should help to clarify the relationships among group size, pup survival, and habitat quality.

Why help?

There is a number of reasons why an individual might remain in its natal territory and partake in rearing later born offspring even if it is unable to reproduce without moving outside of the immediate area in which it was born. If (1) dispersal is risky, (2) the availability of potential mates and breeding areas is low, and/or (3) initial reproductive success is low, there should be selection for delayed dispersal (if ecological conditions permit it) by at least some offspring (a dispersal polymorphism; BROWN 1969, 1974, 1982a; BEKOFF 1977a; ROWLEY 1981; EMLEN 1982 a). If, on the other hand, dispersal is non-risky, the chances of pairing with a conspecific of the opposite sex is high, and initial reproductive success also is high, early dispersal would be expected.

Dispersal by yearling coyotes on our study area (and in other locales) is a risky undertaking (TZILKOWSKI 1980; this study). Furthermore, although both yearling female and male coyotes typically are capable of reproducing, they generally do not contribute much to a given population (for review see BEKOFF 1977b). Yearling female coyotes generally mate later in the breeding season than do older females (YOUNG and DOBYNS 1937; comparative data are lacking for males), and a lower percentage of yearling females ovulate (KENNELLY and JOHNS 1976).

There are insufficient data available to determine reliably what percentage of first year dispersers successfully reproduce and consequently, it is not possible to compare accurately lifetime reproductive success of early versus later breeders. It seems reasonable to assume that a coyote who delays dispersing and breeding until it is 2 or 3 years of age may not necessarily show decreased reproductive success when compared to individuals who disperse as yearlings and attempt to breed when they first become reproductively active. Therefore, observed patterns of emigration, in which some, but not all, individuals disperse from their natal group (if food resources are adequate), is not an unexpected phenomenon (BOWEN 1978, 1981; CAMENZIND 1978; BEKOFF and WELLS 1980, this study; also see STORM et al. 1976; LLOYD 1980).

The potential advantages of helping to rear closely related individuals is obvious, especially in those cases in which helpers' presence leads to an increase in the number of offspring that survive. Even if the correlation between the number of adults attending a den(s) and pup survival is not statistically significant, or barely so, a positive trend may increase helpers' inclusive fitness.

Although kin selection is useful for explaining some examples of helping, there are many exceptions that may be explained as reciprocal altruism (TRIVERS 1971; CONNOR and NORRIS 1982) or as simple reciprocity, selfishness, or mutualism (ROOD 1978; BROWN and BROWN 1980; BROWN 1982a). For example, ROOD found that in a single social unit of dwarf mongooses, unrelated individuals helped to rear pack young, although most helpers were related to the young mongooses. He argued that helpers might benefit from being part of the group with respect to being better protected against predators. Also, helpers that subsequently breed might benefit from receiving help from individuals to whom they had previously provided care (unconscious reciprocity; BROWN 1978; generational mutualism: BROWN 1982a), or from other group members. MALCOLM (1979) also found that in African wild dogs there was little overall relationship between an individual's contribution to rearing and its genetic relatedness to pups. Likewise, BROWN and BROWN (1980) reported that the feeding of fledgling Mexican jays (Aphelocoma ultramarina) was not correlated with relatedness in any obvious, rigorous way. In the present study, male helper B2-1 provided more direct care to halfsiblings than to full-siblings. 
Non-dispersing individuals also might benefit from remaining in their natal area and inheriting breeding space when one of its parents (or other breeder) dies or disperses (BROWN 1969, 1974, 1978, 1982a; STALLCUP and WOOLFENDEN 1978; WOOLFENDEN and FITZPATRICK 1978; ROWLEY 1981; TILSON 1981). If an individual breeds in an area where other potential helpers remain, it might receive some aid in rearing its own offspring.

In the present study, male B2-1 not only increased his inclusive fitness by helping to rear younger siblings and half-siblings; he also inherited a breeding area, paired with a mate with whom he was unrelated, and received help from individuals to whom he previously provided care (male '81, female B36). [Relative rates of occurrence of inbreeding and outbreeding between pack members and between dispersing coyotes are not known. B2-1 never courted his mother when his father was $p$ resent in the pack. Inbreeding has been documented in free-ranging African wild dogs (REICH 1981).]

Additional comparative field data are needed for other coyote populations and for carnivores and mammals, in general. Long-term studies of identified individuals of known genetic relatedness need to be conducted under conditions that permit unobstructed observation if the complex relationships among social organization, development, ecology, space use, dispersal, and helping are to be more completely understood.

\section{Acknowledgments}

This study was supported in part by grants from the NIMH (29571), the NSF (BNS-78-27616, BNS-7923463, BNS-79-05770) the Harry Frank Guggenheim Foundation, the John Simon Guggenheim Memorial Foundation, and by a Faculty Fellowship from the University of Colorado, Boulder. Administrators of the Grand Teton National Park have kindly allowed us to conduct our studies within park boundaries. They also have provided information on carrion availability. Anne BEKOFF, Joel BERGER, and Carol CUNNINGHAM discussed many of the issues raised in this paper and Jerram L. BROWN, Doug CONNER, Tom DANIELS, Les GREENBERG, and Fred HARRINGTON provided helpful comments on a previous draft. Fred HARRINGTON also provided unpublished data from his studies on wolves. Michael C. GRANT performed the statistical and the 3-dimensional analyses, Chris WIELAND and Tony LAVENDER wrote the programs used in SPACE-OUT, and Jan LOGAN drew some of the figures. Jeanie CAVANAGH kindly typed the manuscript.

\section{Literature Cited}

ALEXANDER, R. D., and D. W. TINKLE (eds.) (1981): Natural Selection and Social Behavior. Chiron Press, New York

ALTHOFF, D. P., and P. S. GIPSON (1981): Coyote family spatial relationships with reference to poultry losses. J. Wildl. Manage. 45, 641-649

ANDELT, W. F., D.P. ALTHOFF and P. S. GIPSON (1979): Movements of breeding coyotes with emphasis on den site relationships. J. Mammal. 60, 568-575

ANDERSON, D. J. (1982): The home range: A new nonparametric estimation technique. Ecology 63, 103-112

BEKOFF, M. (1977a): Mammalian dispersal and the ontogeny of individual behavioral phenotypes. Am. Nat. 11, 715-732

BEKOFF, M. (1977b): Canis La trans Say. Mammal. Species 79, 1-9

BEKOFF, M. (1981): Mammalian sibling interactions: Genes, facilitative environments, and the coefficient of familiarity. In: Parental Care in Mammals. (GUAERNICK, D. J., and P. H. KLOPFER, eds.) Plenum Press, New York, pp. 307-346 
BEKOFF, M. (1983): The development of behavior from evolutionary and ecological perspectives: Towards a generic social biology. In: The Comparative Development of Adaptive Skills: Evolutionary Implications. (GOLLIN, E. S., ed.) Acad. Press, New York (in press)

BEKOFF, M., and L. D. MECH (subm.): Simulation analyses of space use and movement patterns

BEKOFF, M., and M. C. WELLS (1980): The social ecology of coyotes. Sci. Am. 242, 130-148

BEKOFF, M., and M. C. WELLS (1981): Behavioural budgeting by wild coyotes: The influences of food resources and social organization. Anim. Behav. 29, 794-801

BEKOFF, M., C. WIELAND and W. A. LAVENDER (1982): Space-out: Graphics programs to study and to simulate space use and movement patterns. Behav. Res. Meth. Instrum. 14, 34-36

BERTRAM, B. C. R. (1976): Kin selection in lions and in evolution. In: Growing Points in Ethology. (BATESON, P. P. G., and R. A. HINDE, eds.) Cambridge Univ. Press, Cambridge, pp. 281-301

BOORMAN, S. A., and P. R. LEVITT (1980): The Genetics of Altruism. Acad. Press, New York

BOWEN, W. D. (1978): Social organization of the coyote in relation to prey size. Ph. D. Diss., Univ. of British Columbia, Vancouver

BOWEN, W. D. (1981): Variation in coyote social organization: The influence of prey size. Canad. J. Zool. $59,639-652$

BOWEN, W. D. (1982): Home range and spatial organization of coyotes in Jasper National Park, Alberta. J. Wildl. Manage. 46, 201-216

BROWN, J. L. (1969): Territorial behavior and population regulation in birds, A review and re-evaluation. Wilson Bull. 81, 293-329

BROWN, J. L. (1974): Alternate routes to sociality in jays - with a theory for the evolution of altruism and communal breeding. Am. Zool. 14, 63-80

BROWN, J. L. (1978): Avian communal breeding systems. Ann. Rev. Ecol. System 9, 123-155

BROWN, J. L. (1980): Fitness in complex avian social systems. In: Evolution in Social Behavior: Hypotheses and Empirical Tests. (MARKL, H., ed.) Verlag Chemie GmbH, Weinheim, pp.115-128

BROWN, J. L. (1982a): Cooperation - A biologist's dilemma. Adv. Study Behav. in press

BROWN, J. L. (1982b): Optimal group size in territorial animals. J. Theor. Bioi. 95, 793-810

BROWN, J. L., and R. P. BALDA (1977): The relationship of habitat quality to group size in Hall's babbler (Pomatostomus halli). Condor 79, 312-320

BROWN, J. L., and E. R. BROWN (1980): Reciprocal aid-giving in a communal bird. Z. Tierpsychol. 53, 313-324

BROWN, J. L., and E. R. BROWN (1981): Kin selection and individual selection in babblers. In: ALEXANDER and TINKLE, pp. 244-256

BROWN, J. L., E. R. BROWN, S. D. BROWN and D. D. Dow (1982): Helpers: Effects of experimental removal on reproductive success. Science $215,421-422$

BROWN, J. L., D. D. DOW, E. R. BROWN and S.D. BROWN (1978): Effects of helpers on feeding of nestlings in the grey-crowned babbler (Pomatostomus temporalis). Behav. Ecol. Sociobiol. 4, 4359

CAMENZIND, F. J. (1978): Behavioral ecology of coyotes on the National Elk Refuge, Jackson, Wyoming. In: Coyotes: Biology, Behavior, and Management. (BEKOFF, M., ed.) Acad. Press, New York, pp. 267-294

CONNOR, R. C., and K. S. NORRIS (1982): Are dolphins reciprocal altruists? Am. Nat. 119, 358-374

DUNN, J. E., and P. S. GIPSON (1977): Analysis of radio telemetry data in studies of home range. Biometrics 33, 85-101

EMLEN, S. T. (1978): The evolution of cooperative breeding in birds. In: Behavioral Ecology: An Evolutionary Approach. (KREBS, J., and N B. DAVIES, eds.) Sinauer, Sunderland, Mass., pp.245-281

EMLEN, S. T. (1981): Altruism, kinship, and reciprocity in the white-fronted bee-eater. In: ALEXANDER and TINKLE, pp. 217- 230 
EMLEN, S. T. (1982a,b): The evolution of helping: I. An ecological constraints model. II. The role of behavioral conflict. Am. Nat. 119, 29-39 and 40-53

EWALD, P. W., G. L. HUNT and M. WARNER (1980): Territory size in western gulls: Importance of intrusion pressure, defense investments, and vegetation structure. Ecology 61, 80-87

FRAME, L. H., J. R. MALCOLM, G. W. FRAME and H. VAN LAWICK (1979): Social organization of African wild dogs (Lycaon pictus) on the Serengeti Plains, Tanzania 1967-1978. Z. Tierpsychol. $50,225-249$

GAINES, M. S., and L. R. MCGLENAGHAN (1980): Dispersal in small mammals. Ann. Rev. Ecol. System 11, 163-196

GARROTT, R. A., and L. E. EBERHARDT (1982): Mortality of arctic fox pups in northern Alaska. J. Mammal. 63, 173-174

HAMILTON, W. D. (1964): The genetical evolution of social behaviour. I and II. J. Theor. Bioi. 7, 1-52

HARRINGTON, F. H., and L. D. MECH (1982): Patterns of homesite attendance in two Minnesota wolf packs. In: Wolves of the World: Perspectives in Behavior, Ecology, and Conservation. (HARRINGTON, F. H., and P. C. PAQUET, eds.) Noyes Publ., Park Ridge, New Jersey (in press)

HARRINGTON, F. H., S. H. FRITTS and L. D. MECH (subm.): Pack size and wolf pup survival: Their relationship under varying ecological conditions

KENNELLY, J. J., and B. E. JOHNS (1976): The estrous cycle of coyotes. J. Wildl. Manage, 40, 272-277

KLEIMAN, D. G. (1977): Monogamy in mammals. Qu. Rev. Bioi. 52, 39-69

KOENIG, W. D., and F. A. PITELKA (1981): Ecological factors and kin selection in the evolution of cooperative breeding in birds. In: ALEXANDER and TINKLE, pp. 261-280

KRUUK, H. (1972): The Spotted Hyena. Univ. of Chicago Press, Chicago

LAMPRECHT, J. (1978): The relationship between food competition and foraging group size in some larger carnivores. Z. Tierpsychol. 46, 337-343

LAMPRECHT, J. (1979): Field observations on the behaviour and social system of the bat-eared fox, Otocyon megalotis Desmarest. Z. Tierpsychol. 49, 260-284

LIGON, J. D. (1981): Demographic patterns and communal breeding in the green woodhoopoe, Phoeniculus purpureus. In: ALEXANDER and TINKLE, pp. 231-243

LIPETZ, V. E., and M. BEKOFF (1982): Group size and vigilance in pronghorns. Z. Tierpsychol. 58, 203216

LLOYD, H. G. (1980): The Red Fox. B. T. Batsford Ltd., London

MACDONALD, D. W. (1979): The flexible social system of the golden jackal, Canis aureus. Behav. Ecol. Sociobiol. 5, 17-38

MACDONALD, D. W. (1980): Social factors affecting reproduction amongst red foxes (Vulpes vulpes L., 1758). In: The Red Fox: Symposium on Behaviour and Ecology. (ZIMEN, E., ed.) Dr. W. Junk B. V. Publ., The Hague, pp. 123-175

MALCOLM, J. (1979): Social organization and the communal rearing of pups in African wild dogs (Lycaon pictus). Ph. D. Diss., Harvard Univ., Cambridge, Mass.

MALCOLM, J., and K. MARTEN (1982): Natural selection and the communal rearing of pups in African wild dogs (Lycaon pictus). Behav. Ecol. Sociobiol. 10, 1-13

MICHENER, G. R. (1979): Spatial relationships and social organization of adult Richardson's ground squirrels. Canad. J. Zool. 57, 125-139

MICHENER, G. R. (1981): Ontogeny of spatial relationships and social behaviour in juvenile Richardson's ground squirrels. Canad. J. Zool. 59, 1666-1676

MOEHLMAN, P. D. (1979): Jackal helpers and pup survival. Nature 277, 382-383

MOEHLMAN, P. D. (1981): Reply to Montgomerie (1981). Nature 289, 825

MOEHLMAN, P. D. (1982): Socioecology of silverbacked and golden jackals (Canis mesomelas, C. aureus). In: Recent Advances in the Study of Mammalian Behavior. (EISENBERG, J., and D. G. KLEIMAN, eds.) Special Publ No. 7, Am. Soc. Mammal. (in press) 
MONTGOMERIE, R. D. (1981): Why do jackals help their parents? Nature 289, 824-825

MYERS, J. P., P. G. CONNORS and F. A. PITELKA (1979): Territory size in wintering sanderlings: The effects of prey abundance and intruder density. The Auk 96, 551-561

OWENS, D. D., and M. J. OWENS (1979): Communal denning and clan associations in brown hyenas (Hyaena bmnnea Thunberg) of the central Kalahari Desert. Afr. J. Ecol. 17, 35-44

REICH, A. (1981): The behavior and ecology of the African wild dog (Lycaon pictus) in the Kruger National Park. Ph. D. Diss., Yale Univ., New Haven, Ct.

REYER, H. U. (1980): Flexible helper structure as an ecological adaptation in the pied kingfisher (Ceryle rudis rudis L.). Behav. Ecol. Sociobiol. 6, 219-227

ROOD, J. P. (1978): Dwarf mongoose helpers at the den. Z. Tierpsychol. 48, 277-287

ROWLEY, I. (1981): The communal way of life in the splendid wren, Malurus splendens. Z. Tierpsychol. $55,228-267$

RYDEN, H. (1975): God's Dog. Coward, McCann, and Geoghegan, New York

SAGGESE, E. P., and B. F. TULLAR (1974): Possible predation of a gray fox on a red fox pup. N. Y. Fish and Game J. 21, 86-87

SCHANTZ, T. VON (1981a): Female cooperation, male competition, and dispersal in the red fox Vulpes vulpes. Oikos 37, 63-68

SCHANTZ, T. VON (1981b): Evolution of group living, and the importance of food and social organization in population regulation; a study on the red fox (Vulpes vulpes). Ph.D. Diss., Lund Univ., Sweden

SKUTCH, A. F. (1935): Helpers at the nest. Auk 52, 257-273

SKUTCH, A. F. (1961): Helpers among birds. Condor 63, 198-226

SOKAL, R. R., and F. J. ROHLF (1981): Biometry. 2nd ed. W. H. Freeman, San Francisco

STACEY, P. B. (1979): Habitat saturation and communal breeding in the acorn woodpecker. Anim. Behav. 27, 1153-1166

STALLCUP, J. A., and G. E. WOOLFENDEN (1978): Family status and contributions to feeding by Florida scrub jays. Anim. Behav. 26, 1144-1156

STORM, G. L., R. D. ANDREWS, R. L. PHILLIPS, R. A. BISHOP, D. B. Siniff and J. R. TESTER (1976): Morphology, reproduction, dispersal, and mortality of mid-western red fox populations. Wildl. Monogr. 49, 1-82

TABORSKY, M., and D. LIMBERGER (1981): Helpers in fish. Behav. Ecol. Sociobiol. 8, 143-145

TILSON, R. L. (1981): Family formation strategies of Kloss's gibbons. Folia Primatol. 35, 259-287

TRIVERS, R. L. (1971): The evolution of reciprocal altruism. Qu. Rev. Bioi. 46, 35-57

TULLAR, B. F., and L. T. BERCHIELLI (1980): Movement of the red fox in central New York. N. Y. Fish Game J. 27, 179-204

TZILKOWSKI, W. M. (1980): Mortality patterns of radio-marked coyotes in Jackson Hole, Wyoming. Ph. D. Diss., Univ. of Massachusetts, Amherst

VEHRENCAMP, S. L. (1979): The roles of individual, kin and group selection in the evolution of sociality. In: Handbook of Behavioral Neurobiology: Social Behavior and Communication. Vol.3. (MARLER, P., and J. C. VANDENBERGH, eds.) Plenum Press, New York, pp. 351-394

WEAVER, J. L. (1979): Influence of elk carrion upon coyote populations in Jackson Hole, Wyoming. In: North American Elk: Ecology, Behavior and Management. (BOYCE, M. S., and L. D. HAYDENWING, eds.) Univ. of Wyoming, Laramie, pp. 152-157

WELLS, M. C., and M. BEKOFF (1981): An observational study of scent marking in free-ranging coyotes. Anim. Behav. 29, 332-350

WELLS, M. C., and M. BEKOFF (1982): Predation by wild coyotes: Behavioral and ecological analyses. J. Mammal. 63, 118-127

WILSON, E. O. (1975): Sociobiology: The New Synthesis. Harvard Univ. Press, Cambridge, Mass.

WITTENBERGER, J. F., and R. L. TILSON (1980): The evolution of monogamy: Hypotheses and evidence. Ann. Rev. Ecol. System 11, 197-232 
WOOLFENDEN, G. E. (1981): Selfish behavior by Florida scrub jay helpers. In: ALEXANDER and TINKLE, pp. 257-260

WOOLFENDEN, G. E., and J. W. FITZPATRICK (1978): The inheritance of territory in group-breeding birds. BioScience 28, 104-108

YOUNG, S. P., and H. W. DOBYNS (1937): Den hunting as a means of coyote control. U.S. Dept. of Agriculture, Leaflet 132, 2-8 